\title{
Editorial
}

\section{Videos in higher education: Making the most of a good thing}

\author{
Matthew Fyfield \\ Faculty of Education, Monash University, Australia \\ Michael Henderson \\ Faculty of Education, Monash University, Australia
}

Eva Heinrich

Massey University, New Zealand

\section{Petrea Redmond}

University of Southern Queensland, Australia

\begin{abstract}
There has been a noticeable rise in the use of, and research into, educational videos in tertiary education in the past decade. This is due in no small part to the reduction of expensive barriers to their production and storage, and an increase in access to streaming services that make videos playable anywhere, anytime. Research into educational videos broadly falls into three categories: improving video design, investigating platforms and technologies that increase student engagement, and developing pedagogical approaches that take full advantage of the affordances of videos. A review of key findings in this journal - considered in light of the broader literature - reveals productive lines of inquiry for future research. Notably, experimental research using the lens of Cognitive Load Theory has established that videos should be short, uncluttered, and restricted to one clearly identified learning goal. There is also robust evidence to suggest videos should be accompanied by learning activities, rather than watched passively. In addition to the experimental research findings there is a wealth of research through case studies, such as exploring video based pedagogies liked flipped and blended learning. However, there are key opportunities for further research, such as the need for replications of experimental design principles in real learning contexts, and the development of pedagogical approaches that utilise the particular affordances of educational videos.
\end{abstract}

Keywords: Video, Screencast, Multimedia, Instructional Video, Educational Video, Cognitive Load

\section{Introduction}

Videos are an increasingly ubiquitous part of higher education. They are used to present factual, conceptual, or procedural content to students (Winslett, 2014), provide flexible learning opportunities (Anderson \& Ellis, 2001; Harrison, 2015), allow input from alternative voices and leading experts (Krauskopf, Zahn, \& Hesse, 2012 ; E. Tan \& Pearce, 2011), provide feedback to students (Henderson \& Phillips, 2015), and allow students to give feedback to instructors (Cochrane \& Bateman, 2010). This increasing use of digital video in higher education is understandable, as with an effective instructional design, videos have regularly been shown to lead to higher learning gains than static media (Castro-Alonso, Wong, Adesope, Ayres, \& Paas, 2019; Höffler \& Leutner, 2007) and live lectures (Craig \& Friehs, 2013). Videos are valued as learning tools by undergraduate students (Henderson, Selwyn, \& Aston, 2015), and can increase student motivation (Abeysekera \& Dawson, 2015). Video has also been reported to have advantages over live demonstrations, when phenomena need to be altered visually before conceptual understanding can occur, such as visualising plant growth or cell division (Lowe \& Schnotz, 2014). Overall, the message is clear that the advent of low cost video hosting, streaming technologies and video authoring tools for both educators and students, offers exciting opportunities to improve learning outcomes in higher education.

Almost twenty years ago, in this journal, Andrewartha and Wilmot (2001) identified that merely replicating lecture content as videos would fail to take full advantage of the particular affordances of digital videos. The authors identified that the "educational characteristics of this new medium promised the possibility of value added instruction" (p. 2), including individualisation, self-pacing, segmentation, interactivity, and active learning. While the technical possibilities around interactivity and personalisation of learning have continued to evolve (Colasante $\&$ Douglas, 2016), the reality is that in practice much of the video produced in higher education remains simple 
lecture capture, often institutionalised by fly-on-the-wall style automated systems (Winslett, 2014). There is great scope for studies into improving the design of videos, developing video platforms and technologies, and investigating pedagogical approaches that take advantage of the particular affordances of digital videos, including when static media may be preferable. These three broad lines of inquiry contribute to the same goal, of finding ways to get the most out of a promising medium. The following sections outline research that has been published in this and other journals about each of these lines of enquiry with videos, and each concludes with a call for further research.

\section{Improving video design}

One approach to the task of improving the actual videos used has been to isolate principles of video design that lead to improvement in learning, as is common in experimental studies using Cognitive Load Theory (Sweller, Van Merrienboer, \& Paas, 1998) or the Cognitive Theory of Multimedia Learning (Mayer, 2014) as a lens. For example, the coherence principle suggests that videos should be focused on a single learning goal, avoiding extraneous material (Mayer \& Fiorella, 2014; Van der Zee, Admiraal, Paas, Saab, \& Giesbers, 2017). Other principles that are well supported in the literature include reducing the length of videos or video segments (Guo, Kim, \& Rubin, 2014; Ibrahim, Antonenko, Greenwood, \& Wheeler, 2012), and explicitly directing the learner's attention towards a particular element of on-screen detail, often termed the signalling or cueing effect (Sharma, Alavi, Jermann, \& Dillenbourg, 2016; Xie et al., 2017). These design principles require educators and instructional designers to engage in considerable planning and editing, and therefore consume more human and capital resources than lecture capture. Because of this level of investment, there is a need for further studies that isolate these principles in instructional videos to ensure that such expenditure is guided by robust research.

While much of the existing literature investigating video design principles has been conducted in experimental laboratory conditions, there is also a need for studies conducted in authentic learning environments. The myriad contextual factors in real learning environments can mediate the learning efficacy of experimentally observed design principles, as shown by papers published in this journal. For example, Kester, and Sharma (2008) found that in a first year astronomy course, including interesting but unnecessary details in an instructional video did not lead to the kind of impairments to learning that they have been shown to in laboratory conditions. Similarly, Stiller, Freitag, Zinnbauer, and Freitag (2009) showed that learner pacing, as is near ubiquitous in online learning platforms, reduces the impact of the modality effect, an experimentally observed effect in which learning outcomes are superior when texts are presented aurally rather than as printed text. This gap between experimental and situated studies needs to be addressed more rigorously. One approach to bridging this gap was shown by Merkt, Weigand, Heier, and Schwan (2011) who replicated their experiments on levels of video interactivity in a quasi-experimental secondary school setting. Such replications of experiments in real learning contexts are needed in higher education and would be welcome in this journal. Beyond the cognitive, there is also need for research into the role of affective dimensions of video design in motivating student interest and the effects that has on learning.

Despite the affordances of videos outlined in this article, there are applications in which video has been shown to overload the cognitive capabilities of learners (Lowe \& Schnotz, 2014). In this journal Kalyuga (2000) identified that some scientific diagrams are better accompanied with static text than dynamic voiceovers, as is common in lecture capture videos. Identifying further contexts in which video is less desirable than other media is a potentially important direction for future research.

\section{Developing video platforms and technologies}

Improving educational videos is only an initial step in making the most out of the medium. Just as important is to investigate platforms and technologies that enhance student engagement by embedding those videos within viewing platforms that demand student engagement beyond passive watching. This has particular merit, as some studies have shown that simply watching a video without integrated learning activities can lead to student overconfidence in learning, without actually leading to meaningful learning gains (Szpunar, Jing, \& Schacter, 2014). Supporting these findings, Huang, Chen, and Ho (2014) published research in this journal demonstrating that combining concept maps with instructional videos in e-textbooks led to greater learning gains than text and diagram designs, but that videos alone were inferior. Papers in this journal have also found that platforms or programs to embed authentic learning activities into videos can improve the effectiveness of the media (Andrewartha \& Wilmot, 2001; Kearny \& Treagust, 2001; Colasante \& Douglas, 2016). For example, Colasante \& Douglas (2016) outlined the purposeful application of a media annotation tool that allows students to collaboratively discuss video case studies, with comments tied to a particular moment or sequence in the video. Given the proliferation of instructional video across all educational sectors, it is clear there needs to be ongoing 
research into the issues and efficacy of video platforms and technologies, particularly in relation to active and immersive learning.

Another line of enquiry focuses on issues of accessibility. For example Gkatzidou and Pearson (2009) found that videos are rarely optimised for students with disabilities, so described a process of adapting instructional videos for such students, through the addition of subtitles, and optimisation of media files for use with accessibility technologies. Since Gkatzidou and Pearson's work, there have been great advancements in automatic captioning technologies on streaming platforms like YouTube (Langworthy, 2017). However, there continues to be a need for studies exploring how video platforms and technologies might be best developed and utilised for the benefit of learners with specific physical, cognitive, emotional and social learning needs. For example, there is room for research into the ways in which vision impaired learners can interact with video content. Moreover, this line of research becomes even more complicated with new developments in video technologies such as recordings of multi-channel streaming (such as recordings of lectures that includes multiple video inputs and text chat), interactive video (such as videos with quizzes), 360 degree and 3D/bi-focal video.

\section{Developing pedagogical approaches}

A search of AJET reveals that the richest contribution this journal has made to the literature on learning with videos is the development of video based pedagogies. In other words, ways in which videos can be integrated into new teaching and learning practices that take advantage of their affordances such as flexibility, learner control, and the ability to show real world phenomena in conceptually accessible formats (such as slowing down or speeding up natural phenomena, see Barnes, 2016). Recently, authors in this journal have made a valuable contribution to critically developing flipped classroom methods.

Flipped learning has been described as a pedagogical system whereby the "information transmission component of a traditional face to face lecture is moved out of class time" (Abeysekera \& Dawson, 2015, p. 1). Taking the place of face to face instruction are active, collaborative tasks. The information is most commonly delivered through the provision of bespoke videos. The advantages of such an approach include learner control over playback, and the increased time available in class for active learning. Authors in AJET have contributed to our understanding of the largely positive student experience of flipped learning (Chen, Chen, \& Chen, 2015; Shih \& Tsai, 2017; Zara, Fox, \& Docherty, 2019), instructor perspectives (Howitt \& Pegrum, 2015; Karabulut-Ilgu, Cherrez, \& Hassall, 2018), and student interaction patterns within flipped classrooms (Er, Kopcha, Orey, \& Dustman, 2015).

More important, perhaps, are the theoretical and practical contributions made by these authors through their descriptions of novel pedagogical practices using flipped learning. For example, in a descriptive account of their experiences in implementing flipped learning in two post-graduate courses Howitt and Pegrum (2015) described the unexpected shift from a pedagogy of speaking to or at students in the traditional lecture context, to a "listening pedagogy" (p. 467). More recently, Zara et al., (2019) described the impact that collaborative activities in class time can have on the attitude of students to the pre-class work. In this research, some participants expressed a perceived social contract or obligation to engage in the pre-class learnings, knowing there would be collaborative activities in class that hinged on their input. Shih \& Tsai (2017) also offer valuable insights into the more subtle nuances of the flipped learning model, such as the reality that students engage more in pre-class videos that are linked to assessment outcomes, and that students can experience an increase in workload.

Beyond flipped learning, there is room for more research into the purposeful design of learning activities using video as a key medium. One example is the use of real-world exemplars as tools for reflection in project based learning. For example, Tan, Tan, and Wettasinghe (2011) outlined a self-directed online unit in which pre-service science teachers developed their understanding of micro-teaching approaches through the analysis of short teaching videos (see also Ma, O'Toole, \& Keppell, 2008). Their reflections on these videos were shared with their peers, and served as the stimulus for the development of lesson plans. Henderson and Phillips (2015) described the use of individualised instructor made videos for feedback to students, and reported that these led to greater student satisfaction, without adding greatly to instructor workload. These various approaches, often investigated using case study and action-research methodologies, demonstrate the potential of video to enhance, rather than simply relocate, pedagogy.

Research describing the opportunities, challenges, and novel methods of video facilitated pedagogies are valuable and are welcome in this journal. Having said this, we do need to caution that there is a tendency in such work to be descriptive and evaluative, rather than analytical. While data about usage and student and instructor perceptions are valuable, they should also be critically analysed - interpreted through theory or conceptual models that help 
to explain why it works. As Chorianopoulos (2018) notes, we need to move towards practice based on theory rather than feasibility or instructor preference. In addition to theoretically sound research, we have also noted an opportunity for the development of innovative methods in such research, including in the analysis of student interactions with media as well as methods for tracking what students do before, during and after watching the video. It would be valuable to instructional designers to know, for instance, whether students in traditional higher education contexts exhibit the same reluctance to watching videos of over six minutes in duration as was shown in MOOCs (Kim et al., 2014). Moreover, despite the dominance of lecture capture video in practice, there are a wide variety of other video styles used in higher education (Chorianopoulos, 2018; Winslett, 2014). Research investigating the impact of these various styles of educational videos in real learning contexts would be valuable.

\section{Conclusion}

Video shows great promise as a powerful medium, not only to communicate content, but also to facilitate the transformation of pedagogical methods. However, we should avoid a "Pollyannaish stance" (Selwyn, 2014, p. 15) that positions this new technology as inherently useful or transformative.

In order to make the most of a promising technology, this editorial has advocated three research directions. The first is to improve the design of actual videos themselves, as a confusing, boring, or poorly produced video is unlikely to contribute to an effective learning environment. Indeed, Lowe and Schnotz (2014) suppose that the rapid uptake of instructional animations and videos is more likely based on "intuition" (p. 532) than a systematic approach to developing good instructional design practices. In reviewing the research in this journal and the broader landscape, we particularly encourage research that:

- isolates principles of video design that lead to improvement in learning,

- includes replications of experiments in real learning contexts,

- explores the role of affective dimensions of video design in motivating student interest and the effects that has on learning.

A second research direction involves the development and application of video technologies to support active learning and super-diverse learners. In particular, we have identified there is a continued need for research in established and emerging forms of video platforms and technologies in terms of:

- helping students to actively construct knowledge, rather than passively watching,

- $\quad$ benefiting learners with specific physical, cognitive, emotional, and social learning needs.

The third research direction is that there needs to be a focus on developing pedagogical approaches that take advantage of the particular affordances of video. In particular, we encourage further research that:

- $\quad$ explores pedagogical applications that take advantage of learner control, flexibility of access, student collaborative video production, or subject matter that benefits from the dynamic temporal nature of video,

- adopts a theoretical lens to explain why an intervention was successful or not, and how it might be applied to different contexts.

While these three research directions are presented here as discrete, they are of course inextricably linked. In real contexts, any educator choosing to use video as part of their practice will need to make decisions, whether active or determined by organisational demands, about video design, delivery technology, and pedagogical approach. We seek contributions to the development of any of these elements of teaching with video, or ways in which they can be considered together. Only then can we say we are moving towards making the most of a good thing.

\section{Acknowledgements}

The production of AJET is a large team effort. The lead editors Associate Professor Eva Heinrich, Associate Professor Michael Henderson, and Associate Professor Petrea Redmond work with a committed team of associate editors who facilitate the reviews and author revisions of papers: Dr Thomas Donald Cochrane, Dr Linda Corrin, Dr. Eamon Costello, Dr Christopher E Dann, Associate Professor Teresa S Foulger, Associate Professor Paul Gruba, Professor Judi Harris, Dr Henk Huijser, Associate Professor Matthew Kearney, Dr Chien-Ching Lee, Associate Professor Jason M Lodge, Associate Professor Lina Markauskaite, Associate Professor Stephen Marshall, Dr Michael Phillips, Dr Kate Thompson, Professor Joke Voogt. Backing up the editorial team we have two dedicated copyeditors, Kayleen Wood and Antonina Petrolito who work closely with authors to enhance the quality of the articles by ensuring the text is concise, consistent, and accurate. We also need to thank our large 
number of expert reviewers who ensure our articles are of high standard. And finally, thank you to the authors, who offer valuable new understandings in the field of educational technology.

\section{References}

Abeysekera, L., \& Dawson, P. (2015). Motivation and cognitive load in the flipped classroom: definition, rationale and a call for research. Higher Education Research \& Development, 34(1), 1-14. https://doi.org/10.1080/07294360.2014.934336.

Anderson, A. J., \& Ellis, A. (2001). Using desktop video to enhance music instruction. Australasian Journal of Educational Technology, 17(3). https://doi.org/10.14742/ajet.1796.

Andrewartha, G., \& Wilmot, S. (2001). Can multimedia meet tertiary educational needs better than the conventional lecture? A case study. Australasian Journal of Educational Technology, 17(1). https://doi.org/10.14742/ajet.1769.

Barnes, S. R. (2016). Studies in the Efficacy of Motion Graphics: The Effects of Complex Animation on the Exposition Offered by Motion Graphics. Animation, 11(2), 146-168. https://doi.org/10.1177/1746847716637823.

Castro-Alonso, J. C., Wong, M., Adesope, O. O., Ayres, P., \& Paas, F. (2019). Gender Imbalance in Instructional Dynamic Versus Static Visualizations: a Meta-analysis. Educational Psychology Review, 31(2), 361-387. https://doi.org/10.1007/s10648-019-09469-1.

Chen, L., Chen, T.-L., \& Chen, N.-S. (2015). Students' perspectives of using cooperative learning in a flipped statistics classroom. Australasian Journal of Educational Technology, 31(6). https://doi.org/10.14742/ajet.1876.

Chorianopoulos, K. (2018). A Taxonomy of Asynchronous Instructional Video Styles. The International Review of Research in Open and Distributed Learning, 19(1), 294-311. https://doi.org/10.19173/irrodl.v19i1.2920.

Cochrane, T., \& Bateman, R. (2010). Smartphones give you wings: Pedagogical affordances of mobile Web 2.0. Australasian Journal of Educational Technology, 26(1). https://doi.org/10.14742/ajet.1098.

Colasante, M., \& Douglas, K. (2016). Prepare-Participate-Connect: Active learning with video annotation. Australasian Journal of Educational Technology, 32(4). https://doi.org/10.14742/ajet.2123.

Craig, C. L., \& Friehs, C. G. (2013). Video and HTML: Testing online tutorial formats with biology students. Journal of Web Librarianship, 7(3), 292-304. https://doi.org/10.1080/19322909.2013.815112.

Er, E., Kopcha, T. J., Orey, M., \& Dustman, W. (2015). Exploring college students' online help-seeking behavior in a flipped classroom with a web-based help-seeking tool. Australasian Journal of Educational Technology, 31(5), 458-469. https://doi.org/10.14742/ajet.2527.

Gkatzidou, S., \& Pearson, E. (2009). The potential for adaptable accessible learning objects: A case study in accessible vodcasting. Australasian Journal of Educational Technology, 25(2). https://doi.org/10.14742/ajet.1155.

Guo, P. J., Kim, J., \& Rubin, R. (2014). How video production affects student engagement: An empirical study of mooc videos. Paper presented at the Proceedings of the first ACM conference on Learning@ scale conference. https://doi.org/10.1145/2556325.2566239.

Harrison, D. J. (2015). Assessing experiences with online educational videos: Converting multiple constructed responses to quantifiable data. The International Review of Research in Open and Distributed Learning, 16(1). https://doi.org/doi.org/10.19173/irrodl.v16i1.1998.

Henderson, M., \& Phillips, M. (2015). Video-based feedback on student assessment: scarily personal. Australasian Journal of Educational Technology, 31(1). https://doi.org/doi.org/10.14742/ajet.1878.

Henderson, M., Selwyn, N., \& Aston, R. (2015). What works and why? Student perceptions of 'useful' digital technology in university teaching and learning. Studies in Higher Education, 42(8), 1567-1579. https://doi.org/10.1080/03075079.2015.1007946.

Höffler, T. N., \& Leutner, D. (2007). Instructional animation versus static pictures: A meta-analysis. Learning and Instruction, 17(6), 722-738. https://doi.org/10.1016/j.learninstruc.2007.09.013.

Howitt, C., \& Pegrum, M. (2015). Implementing a flipped classroom approach in postgraduate education: An unexpected journey into pedagogical redesign. Australasian Journal of Educational Technology, 31(4), 458-469. https://doi.org/10.14742/ajet.2439.

Huang, K.-L., Chen, K.-H., \& Ho, C.-H. (2014). Enhancing learning outcomes through new e-textbooks: A desirable combination of presentation methods and concept maps. Australasian Journal of Educational Technology, 30(5). https://doi.org/doi.org/10.14742/ajet.538.

Ibrahim, M., Antonenko, P. D., Greenwood, C. M., \& Wheeler, D. (2012). Effects of segmenting, signalling, and weeding on learning from educational video. Learning, media and technology, 37(3), 220-235. https://doi.org/10.1080/17439884.2011.585993. 
Kalyuga, S. (2000). When using sound with a text or picture is not beneficial for learning. Australasian Journal of Educational Technology, 16(2). https://doi.org/doi.org/10.14742/ajet.1829.

Karabulut-Ilgu, A., Cherrez, N. J., \& Hassall, L. (2018). Flipping to engage students: Instructor perspectives on flipping large enrolment courses. Australasian Journal of Educational Technology, 34(4), 123-137. https://doi.org/10.14742/ajet.4036.

Kay, R. H. (2012). Exploring the use of video podcasts in education: A comprehensive review of the literature. Computers in Human Behavior, 28(3), 820-831. https://doi.org/10.1016/j.chb.2012.01.011.

Kearney, M., \& Treagust, D. F. (2001). Constructivism as a referent in the design and development of a computer program using interactive digital video to enhance learning in physics. Australasian Journal of Educational Technology, 17(1). https://doi.org/10.14742/ajet.1773.

Kim, J., Guo, P. J., Seaton, D. T., Mitros, P., Gajos, K. Z., \& Miller, R. C. (2014). Understanding in-video dropouts and interaction peaks inonline lecture videos. Paper presented at the Proceedings of the first ACM conference on Learning@ scale conference. https://doi.org/10.1145/2556325.2566237.

Krauskopf, K., Zahn, C., \& Hesse, F. W. (2012). Leveraging the affordances of Youtube: The role of pedagogical knowledge and mental models of technology functions for lesson planning with technology. Computers \& Education, 58(4), 1194-1206. https://doi.org/doi.org/10.1016/j.compedu.2011.12.010.

Langworthy, S. (2017). Do You YouTube? The Power of Brief Educational Videos for Extension. Journal of Extension, 55(2), n2. Retrieved from https://joe.org/.

Lowe, R., \& Schnotz, W. (2014). Animation principles in multimedia learning. In Cambridge handbooks in psychology. The Cambridge handbook of multimedia learning (2nd Edition ed., pp. 513-546). New York: Cambridge University Press. https://doi.org/10.1017/CBO9781139547369.026.

Ma, A. K. F., O'Toole, J., \& Keppell, M. (2008). An investigation of student teachers' attitudes to the use of media triggered problem based learning. Australasian Journal of Educational Technology, 24(3). https://doi.org/doi.org/10.14742/ajet.1211.

Mayer, R. E. (2014). The Cambridge handbook of multimedia learning (2nd Edition ed.). Cambridge: Cambridge university press. https://doi.org/10.1017/CBO9781139547369.

Mayer, R. E., \& Fiorella, L. (2014). Principles for reducing extraneous processing in multimedia learning: coherence, signalling, redundancy, spatial contiguity and temporal contiguity principles. In R. E. Mayer (Ed.), The Cambridge handbook of multimedia learning (pp. 279-315). New York: Cambridge University Press. https://doi.org/10.1017/CBO9781139547369.015.

Merkt, M., Weigand, S., Heier, A., \& Schwan, S. (2011). Learning with videos vs. learning with print: The role of interactive features. Learning and Instruction, 21(6), 687-704. https://doi.org/10.1016/j.learninstruc.2011.03.004.

Muller, D. A., Lee, K. J., \& Sharma, M. D. (2008). Coherence or interest: Which is most important in online multimedia learning? Australasian Journal of Educational Technology, 24(2). https://doi.org/doi.org/10.14742/ajet.1223.

Selwyn, N. (2014). Distrusting educational technology: Critical questions for changing times. New York: Routledge. https://doi.org/doi.org/10.4324/9781315886350.

Sharma, K., Alavi, H. S., Jermann, P., \& Dillenbourg, P. (2016). A gaze-based learning analytics model: invideo visual feedback to improve learner's attention in MOOCs. Paper presented at the Proceedings of the Sixth International Conference on Learning Analytics \& Knowledge. https://doi.org/10.1145/2883851.2883902.

Shih, W.-L., \& Tsai, C.-Y. (2017). Students' perception of a flipped classroom approach to facilitating online project-based learning in marketing research courses. Australasian Journal of Educational Technology, 33(5), 32-49. https://doi.org/10.14742/ajet.2884.

Stiller, K. D., Freitag, A., Zinnbauer, P., \& Freitag, C. (2009). How pacing of multimedia instructions can influence modality effects: A case of superiority of visual texts. Australasian Journal of Educational Technology, 25(2). https://doi.org/doi.org/10.14742/ajet.1149.

Sweller, J., Van Merrienboer, J. J., \& Paas, F. G. (1998). Cognitive architecture and instructional design. Educational Psychology Review, 10(3), 251-296. https://doi.org/10.1023/A:1022193728205.

Szpunar, K. K., Jing, H. G., \& Schacter, D. L. (2014). Overcoming overconfidence in learning from videorecorded lectures: Implications of interpolated testing for online education. Journal of Applied Research in Memory and Cognition, 3(3), 161-164. https://doi.org/10.1016/j.jarmac.2014.02.001.

Tan, A.-L., Tan, S.-C., \& Wettasinghe, M. (2011). Learning to be a science teacher: Reflections and lessons from video-based instruction. Australasian Journal of Educational Technology, 27(3). https://doi.org/doi.org/10.14742/ajet.954.

Tan, E., \& Pearce, N. (2011). Open education videos in the classroom: exploring the opportunities and barriers to the use of YouTube in teaching introductory sociology. Research in Learning Technology, 19(1), 125133. https://doi.org/10.3402/rlt.v19s1/7783. 
Van der Zee, T., Admiraal, W., Paas, F., Saab, N., \& Giesbers, B. (2017). Effects of subtitles, complexity, and language proficiency on learning from online education videos. Journal of Media Psychology, 29, 18-30. https://doi.org/10.1027/1864-1105/a000208.

Winslett, G. (2014). What counts as educational video?: Working toward best practice alignment between video production approaches and outcomes. Australasian Journal of Educational Technology, 30(5). https://doi.org/10.14742/ajet.458.

Xie, H., Wang, F., Hao, Y., Chen, J., An, J., Wang, Y., \& Liu, H. (2017). The more total cognitive load is reduced by cues, the better retention and transfer of multimedia learning: A meta-analysis and two metaregression analyses. PloS one, 12(8), e0183884. https://doi.org/10.1371/journal.pone.0183884.

Zara, P. A., Fox, W. H., \& Docherty, P. D. (2019). Student perspectives of independent and collaborative learning in a flipped foundational engineering course. Australasian Journal of Educational Technology, 35(5), 79-94. https://doi.org/10.14742/ajet.3804.

Corresponding author: Matthew Fyfield, Matthew.Fyfield@monash.edu

Copyright: Articles published in the Australasian Journal of Educational Technology (AJET) are available under Creative Commons Attribution Non-Commercial No Derivatives Licence (CC BY-NC-ND 4.0). Authors retain copyright in their work and grant AJET right of first publication under CC BY-NC-ND 4.0.

Please cite as: Fyfield, M., Henderson, M., Heinrich, E., \& Redmond, P. (2019). Videos in higher education: Making the most of a good thing. Australasian Journal of Educational Technology, 35(5), 1-7. https://doi.org/10.14742/ajet.5930 